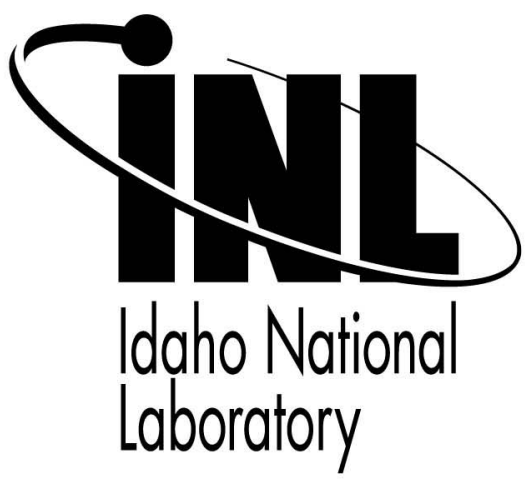

\title{
Design of a Compact Heat Exchanger for Heat Recuperation from a High Temperature Electrolysis System
}

IMECE 2008

\author{
G. K. Housley \\ J. E. O'Brien \\ G. L. Hawkes
}

November 2008

This is a preprint of a paper intended for publication in a journal or proceedings. Since changes may be made before publication, this preprint should not be cited or reproduced without permission of the author. This document was prepared as an account of work sponsored by an agency of the United States Government. Neither the United States Government nor any agency thereof, or any of their employees, makes any warranty, expressed or implied, or assumes any legal liability or responsibility for any third party's use, or the results of such use, of any information, apparatus, product or process disclosed in this report, or represents that its use by such third party would not infringe privately owned rights. The views expressed in this paper are not necessarily those of the United States Government or the sponsoring agency. 


\title{
DESIGN OF A COMPACT HEAT EXCHANGER FOR HEAT RECUPERATION FROM A HIGH TEMPERATURE ELECTROLYSIS SYSTEM
}

\author{
G.K. Housley, J.E. O'Brien, G. L. Hawkes \\ Idaho National Laboratory \\ Idaho Falls, ID 83415, USA
}

\begin{abstract}
Design details of a compact heat exchanger and supporting hardware for heat recuperation in a high-temperature electrolysis application are presented. The recuperative heat exchanger uses a vacuum-brazed plate-fin design and operates between 300 and $800^{\circ} \mathrm{C}$. It includes corrugated inserts for enhancement of heat transfer coefficients and extended heat transfer surface area. Two recuperative heat exchangers are required per each four-stack electrolysis module. The heat exchangers are mated to a base manifold unit that distributes the inlet and outlet flows to and from the four electrolysis stacks. Results of heat exchanger design calculations and assembly details are also presented.
\end{abstract}

\section{NOMENCLATURE}

$f \quad$ friction factor

$F \quad$ Faraday number, $96487 \mathrm{C} / \mathrm{mol}$

$K \quad$ permeability, $\mathrm{m}^{2}$

$\mathrm{H} \quad$ square sub-channel height, $\mathrm{mm}$

$\Delta \dot{N}_{H_{2}} \quad$ molar hydrogen production rate, mol/s

$N_{\text {cells }} \quad$ number of electrolysis cells

$R e_{D h} \quad$ Reynolds number based on hydraulic diameter

$Q_{H 2 O} \quad$ steam volumetric flow rate, slpm

$Q_{H 2} \quad$ hydrogen volumetric flow rate, slpm

$U_{H 2 O} \quad$ steam utilization

$y_{H 2, \text { in }} \quad$ inlet hydrogen mole fraction

$\rho_{M} \quad$ standard volumetric density, $\mathrm{mol} / \mathrm{m}^{3}$

\section{INTRODUCTION}

In order to assess the feasibility of high-temperature steam electrolysis for high-efficiency hydrogen production using nuclear energy, researchers at the Idaho National Laboratory (INL) have been developing an experimental test capability to address the research and scale-up issues associated with the implementation of solid-oxide electrolysis cell technology for hydrogen production from steam. This work is supported by the US Department of Energy Nuclear Hydrogen Initiative (NHI).

To date, research at the INL has progressed from singlecell testing to short stacks to multiple-stack advanced test capabilities of an Integrated Laboratory Scale (ILS) facility built in 2007. The purpose of the ILS facility is to study some of the integral issues to be encountered in large-scale hydrogen-production plants such as thermal management, hotzone design, multiple-stack electrical configuration, preheating of process gases, hydrogen recycle, and heat recuperation.

In 2007, successful tests were completed in the ILS with a single four-stack, 240-cell electrolysis module. Results of this test were presented in [1]. Scale-up to three electrolysis modules is under way. As part of this scale-up, plans were developed to include heat recuperation, in which the inlet process gases are heated to the electrolyzer operating temperature of $800-850^{\circ} \mathrm{C}$ via heat transfer with the outlet process gases. In a large-scale high-temperature electrolysis (HTE) plant, heat recuperation will be absolutely critical in order to minimize the plant net heat requirement and maximize the overall hydrogen production efficiency [2]. In the ILS, incorporation of heat recuperation is also beneficial from an operational standpoint because it reduces the required outlet temperature of the electrically heated steam superheater and it minimizes the thermal load on the hot zone base plate.

\section{CONCEPT DESIGN}

In the ILS experiment, the three four-stack electrolysis modules are mounted inside of an electrically heated hot zone enclosure. Two gas streams feed into each of the electrolysis modules: a steam/hydrogen process stream and an air sweepgas stream. Hydrogen ( $\sim 10 \%$ by volume) is included in the inlet process gas stream in order to maintain reducing conditions on the steam/hydrogen electrodes. In a large-scale 
plant, this would be accomplished by recirculating a fraction of the hydrogen produced in the HTE process back to the inlet gas stream. In the solid oxide electrolysis cells, steam is electrochemically reduced on the cathode side of the cells, leaving hydrogen as a product stream and yielding oxygen on the anode side of the cells. The air sweep-gas stream is used to sweep away the evolved oxygen. The air sweep stream can also be used to provide heat to the cells in order to balance the endothermic heat requirement of the electrochemical steam reduction reaction.

An internally manifolded plate-fin design concept was selected for this heat recuperator application. This design provides excellent configuration flexibility in terms of selecting the number of flow elements per pass and the total number of passes in order to satisfy the heat transfer and pressure drop requirements. Theoretical counterflow heat exchanger performance can be approached with this design. This design can also accommodate multiple fluids in a single unit.

One problem with this application is the fact that the mass flow rate of the process stream decreases as steam is converted to hydrogen, since the oxygen passes through the electrolyte in the form of oxygen ions, evolving on the opposite side of the cells. Consequently, the heat capacity rate of the outgoing hydrogen is lower than that of the incoming steam. Therefore, it is not possible to preheat the incoming steam completely to the HTE process temperature using only the outgoing hydrogen. For this reason, an initial concept was developed that would include both inlet streams and both outlet streams in a single heat exchanger. Having four ports on each end of the heat exchanger, for a total of eight ports, would allow the two incoming streams to be heated by both outgoing steams. With just one pattern as shown in Fig. 1, the rim piece could be rotated in four different orientations to allow gas flow back and forth through a single heat exchanger. For example, the inlet

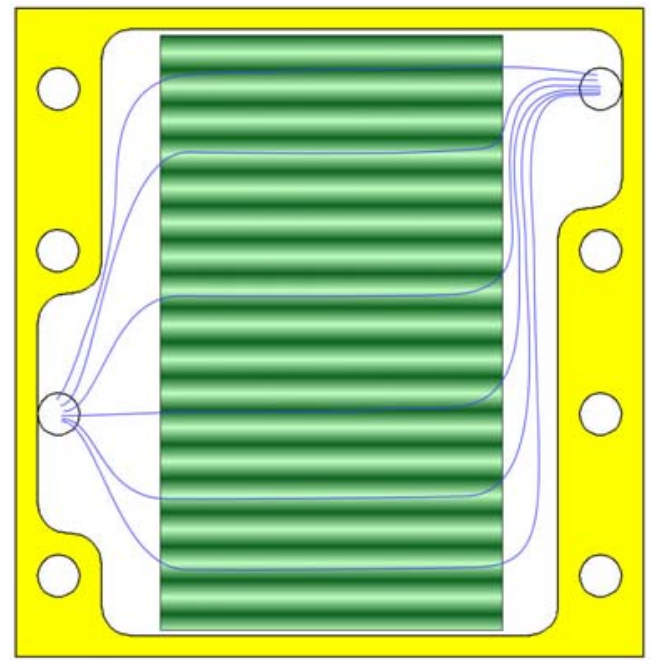

Figure 1. Four-stream heat exchanger channel, showing corrugated insert and flow distribution. steam could flow through the bottom channel, outlet air through the next channel, inlet air through the next channel, and outlet hydrogen through the fourth channel. The sequence would then repeat, depending on the required number of elements per pass and number of passes. Each flow channel includes a thin corrugated insert that forms numerous small individual sub-channels that improve flow distribution, increase heat transfer coefficients, and provide additional heat transfer surface area.

Despite the potential advantages of the four-fluid design, we ultimately elected to proceed with two separate but identical heat exchangers for each electrolyzer module: one for steam and hydrogen, the second for air and air/oxygen. This choice was based primarily on concerns over the possibility of air and hydrogen mixing in the event of a leak, potentially yielding a combustible mixture.

\section{DESCRIPTION OF THE HEAT RECUPERATION SYSTEM}

An illustration of a single flow channel for the two-stream design is provided in Fig. 2. Flow can enter either from the lower right and proceed to upper left, as shown in the figure, or after flipping the rim piece, from lower left to upper right, in cross-flow. Note that the flow channel again includes a corrugated insert designed to improve flow distribution, increase heat transfer coefficients, and provide increased heat transfer surface area.

An exploded view of the two-fluid heat exchanger is provided in Fig. 3. Cold fluid enters from the bottom, hot fluid from the top. This view shows a design that includes three flow elements per pass and four passes. This configuration was selected based on heat transfer and pressure drop design calculations. From the standpoint of heat transfer, a single element per pass with multiple passes would be best, but for our application, the pressure drop was too high to support that design. Pressure drop is a concern primarily on the downstream side of the electrolyzer. If the downstream pressure drop is too high, leakage can occur in the electrolysis stacks. The opposite extreme of a single pass with multiple flow channels provides the lowest pressure drop, but much lower heat transfer performance. Furthermore, this concept

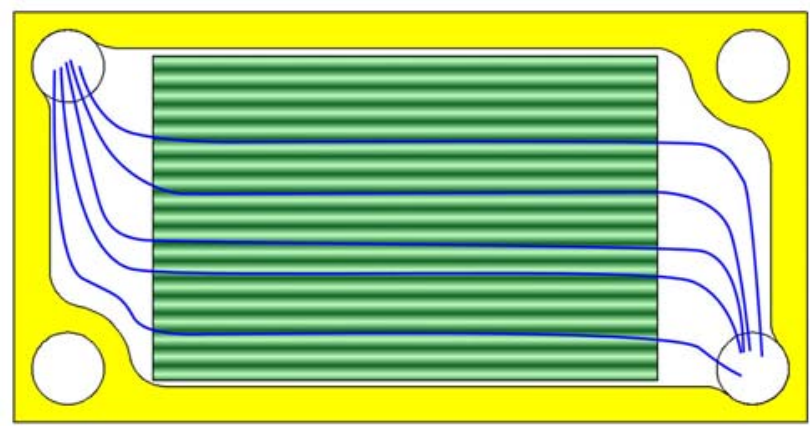

Figure 2. Two-stream heat exchanger channel, showing corrugated insert and flow distribution 


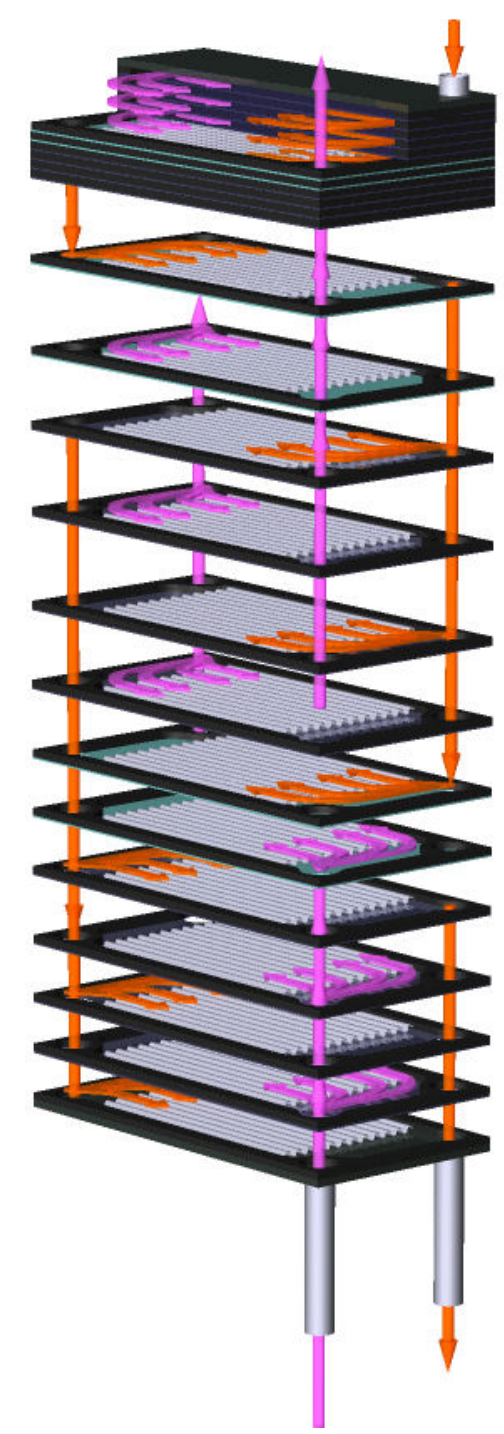

Figure 3. Two-stream heat exchanger concept.

would negate one of the primary objectives of the heat exchangers, which is to protect the hot-zone base plate from exposure to the highest gas temperatures.

Most of the adjacent flow channels shown in Fig. 3 are in counter-flow, but this design necessitates that there will be one parallel-flow channel per pass. The parallel-flow channels are located at the interface between passes, where the flow direction changes.

An exploded assembly drawing of the heat exchanger is provided in Fig. 4. The heat exchanger consists of a stacked arrangement of thin plates that are assembled and vacuumbrazed together. The top plate includes two small tubes that mate with corresponding holes in the bottom of an electrolyzer module base manifold unit. One of these holes is the hot-gas outlet from the electrolyzer module. The other is the process gas inlet to the electrolyzer. Each flow channel is formed from an assembly of two separator plates, a hollow rim piece and a thin corrugated sheet sandwiched between the separator plates. The internal dimensions of each rim piece are 4.70 -inch wide

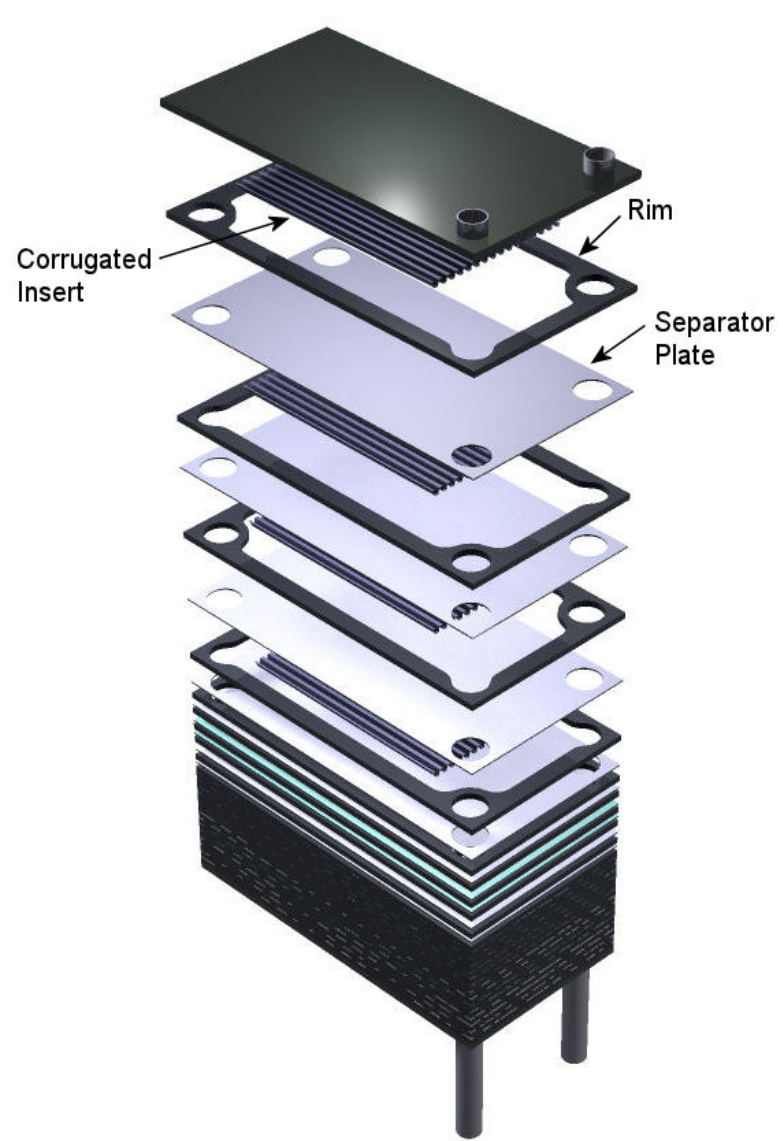

Figure 4. Exploded view of heat exchanger showing rim pieces, corrugated inserts, and separator plates.

and 10.0-inch long. For the specific layout shown, the flow channel height is $0.187 \mathrm{in}$. This dimension is equal to the peak-to-peak height of the corrugated inserts. The corrugations create 24 small individual flow sub-channels within each flow layer. The small channels serve as flow distributors and provide enhanced heat transfer due to an increase in heat transfer coefficient and extended-surface heat transfer area. Flow enters each of the rim pieces from a 1.00inch diameter hole in one of the four corners. At each layer, two of the holes are surrounded by solid rim material and two are open. By orienting the rim pieces appropriately at each level, a counterflow arrangement can be achieved with one or more flow elements per pass and one or more passes. This flexibility allows for optimization of total heat transfer and pressure drop. Note that of the nine possible configurations for each layer, there are only four distinct pieces that need to be fabricated. The other configurations are accomplished by simply flipping one of the four pieces either horizontally or vertically. The overall configuration shown in Fig. 4 yields three elements per pass and four passes for both the hot process gas and the cold process gas, for a total of 24 flow passages.

As already discussed, there will be two separate heat exchangers for each four-stack electrolysis module. The first heat exchanger will exchange heat between in-coming steam 
and out-going hydrogen. The second heat exchanger, identical to the first, will exchange heat between in-coming air and outgoing air/oxygen.

\section{HEAT EXCHANGER DESIGN CALCULATIONS}

Design calculations were performed in order to estimate the heat transfer and pressure-drop performance of the recuperative heat exchanger. Initial one-dimensional heat transfer calculations were based on the effectiveness-NTU method. Gas mixture properties were evaluated at $850^{\circ} \mathrm{C}$. On the process-gas side, the cold inlet steam-hydrogen mixture composition was assumed to be $10 \%$ hydrogen and $90 \%$ steam by volume. The hot outlet steam-hydrogen mixture was assumed to be $45 \%$ steam and $55 \%$ hydrogen, which corresponds to $50 \%$ steam utilization. A nominal current density of $0.25 \mathrm{~A} / \mathrm{cm}^{2}$ and a cell area of $64 \mathrm{~cm}^{2}$ was assumed. The molar hydrogen production rate can then be calculated from Faraday's law:

$$
\Delta \dot{N}_{H_{2}}=\frac{I}{2 F} N_{\text {cells }}
$$

where $F$ is the Faraday number. The required steam inlet volumetric flow rate follows from the assumed utilization value:

$$
Q_{H_{2} \mathrm{O}}=\frac{\Delta \dot{N}_{\mathrm{H}_{2}}}{U_{\mathrm{H}_{2} \mathrm{O}} \rho_{M}}
$$

The inlet volumetric flow rate for hydrogen, based on an assumed hydrogen inlet mole fraction can then be obtained from:

$$
Q_{H_{2}}=\frac{y_{H_{2}, \text { in }}}{1-y_{H_{2}, \text { in }}} Q_{H_{2} O}
$$

The outlet flow rates of steam and hydrogen follow directly from the hydrogen production rate, which is equal and opposite to the steam consumption rate on a molar basis. Base-case flow rates based on these equations are presented in Table 1.

On the air side, the molar oxygen production rate is equal to one-half of the molar hydrogen production rate. The inlet sweep-gas flow rate of air can then be scaled to ensure that the outlet composition of oxygen is below a certain value. High air-side mole fractions of oxygen can accelerate oxidation at the temperatures that are associated with the electrolysis application. An outlet sweep-gas oxygen mole fraction limit of $48 \%$ was assumed for these calculations.

The one-dimensional heat transfer calculations were performed by considering the flow through a single subchannel of the corrugated insert. For the electrolysis application, with the specified heat exchanger dimensions, the Reynolds numbers in these sub-channels were very low (4070), so the assumption of laminar flow is valid. The corrugated sub-channels were approximated as square ducts with a corresponding laminar-flow Nusselt number of 3.61.
Table 1. Base-case flow rates.

\begin{tabular}{|l|l|l|l|l|}
\hline & $\begin{array}{l}Q_{H 2 O} \\
(\text { SLPM })\end{array}$ & $\begin{array}{l}Q_{H 2} \\
(\text { SLPM })\end{array}$ & $\begin{array}{l}Q_{\text {air }} \\
(\text { SLPM })\end{array}$ & $\begin{array}{l}Q_{\text {air } / O 2} \\
(\text { SLPM })\end{array}$ \\
\hline inlet & 53.5 & 5.95 & 25.5 & \\
\hline outlet & 26.8 & 32.7 & & 38.9 \\
\hline
\end{tabular}

An overall heat transfer coefficient was then estimated, accounting for the fin effect of the sub-channel side walls. After obtaining the hot and cold fluid heat capacity rates based on the known gas flow rates, heat exchanger effectiveness values can be obtained [e.g., 3]. The calculations were performed for both counter-flow and parallel-flow situations.

For counterflow, estimated heat exchanger effectiveness values for the base case were 0.977 for the steam-hydrogen heat exchanger and 1.0 for the air-oxygen heat exchanger. Assuming a cold inlet temperature of $300^{\circ} \mathrm{C}$ for the electrolyzer inlet streams, the steam-hydrogen heat exchanger outlet temperature was estimated to be $734^{\circ} \mathrm{C}$ and the air heat exchanger outlet temperature was $800^{\circ} \mathrm{C}$. The corresponding steam-hydrogen outlet temperature prediction for parallel-flow was only $535^{\circ} \mathrm{C}$. Full preheating of the inlet air stream is possible because the air-oxygen outlet stream has a higher heat capacity rate due to the oxygen addition. Parallel-flow results were much less favorable.

The use of the heat recuperation concept does impose an additional demand on the hot zone enclosure heaters compared to the no-heat-exchanger case in which the inlet gases are externally preheated to $800^{\circ} \mathrm{C}$ before entering the hot zone. For the base case considered, the total additional thermal duty is about $1.77 \mathrm{~kW}$ with all six heat exchangers in operation, again assuming a $300^{\circ} \mathrm{C}$ heat exchanger inlet temperature. For comparison, the heater power required to externally preheat all of the inlet gas streams from $300^{\circ} \mathrm{C}$ to $800^{\circ} \mathrm{C}$ upstream of the hot zone would be $6.94 \mathrm{~kW}$, not even accounting for the inevitable heat losses that would occur between the superheater exit and the hot zone inlet.

Pressure drop in the flow sub-channels was obtained by assuming laminar flow in a square channel for which $f=$ $64 / R e_{D h}$. Sub-channel pressure-drop values ranged from $0.2-$ 0.35 in $\mathrm{H}_{2} \mathrm{O}$, which were within the target range. Additional pressure drop occurs in the transition regions between the flow in the sub channels and the flow through the circular-crosssection holes in the separator plates.

\section{CFD MODEL}

In order to account for three-dimensional flow and axial heat conduction, and to properly account for the parallel-flow channels, a computational fluid dynamic model of the recuperative heat exchanger was developed using the commercial CFD code FLUENT. Governing equations were provided by the core FLUENT mass, momentum, and energy equations for laminar flow. The small channels formed by the corrugated inserts were modeled as a porous media region with a permeability based on laminar flow in square channels given by 

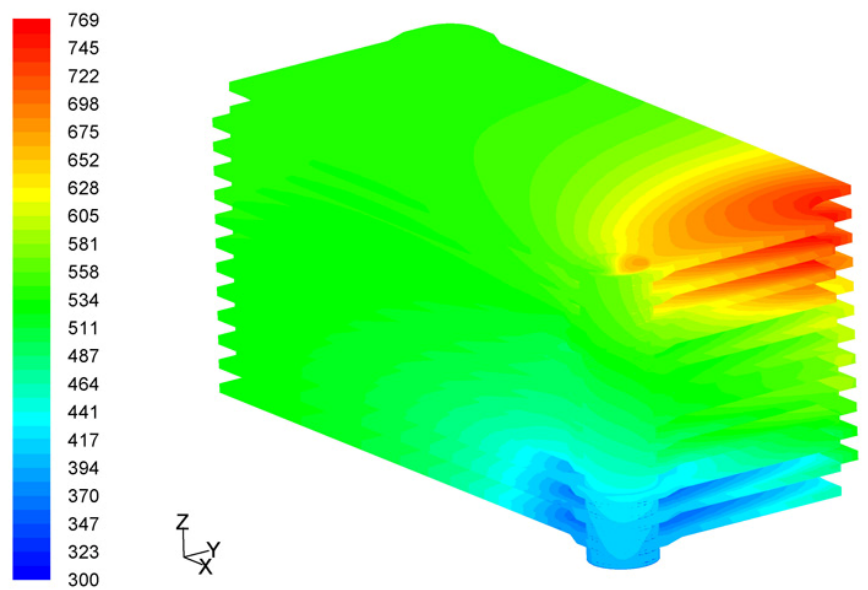

Figure 5. Temperature contours $\left({ }^{\circ} \mathrm{C}\right)$ in steam flow channels obtained from FLUENT model for 3 elements per pass and 4 passes.

$$
K=H^{2} / 32
$$

where $\mathrm{H}$ is the width of the square channels. Using the channel width dimension of $4.37 \mathrm{~mm}$, this yields a permeability value of $5.96 \times 10^{-7} \mathrm{~m}^{2}$. The FLUENT model included 950,000 cells. An adiabatic boundary condition was applied around the periphery of the heat exchanger. All fluid properties were specified to vary with temperature. The numerical model converged in 53 iterations using 30 singleprocessor CPU minutes with a residual on mass conservation of $1 \times 10^{-7}$.

Temperature contours in the steam flow channels are presented in Fig. 5 for the base case design. Based on these contours, it appears that most of the heat transfer is occurring near the cold and hot inlets. Temperatures in the central region of the heat exchanger are relatively uniform. The steam outlet temperature predicted by the CFD model for the base case is $611^{\circ} \mathrm{C}$, which is between the one-dimensional counter-flow and parallel-flow results, as expected. Predicted pressure drop values for the steam and hydrogen sides were 285 and $252 \mathrm{~Pa}$, respectively.

\section{DESCRIPTION OF THE ILS BASE MANIFOLD ASSEMBLY}

In the electrolyzer application, the recuperative heat exchangers will be mated to a base manifold unit that will distribute the inlet and outlet flows to and from the electrolysis stacks. In each module, the two heat exchangers are mated to a single base manifold unit. An exploded view of the base manifold unit is presented in Fig. 6. By means of a vacuumbrazed three-chamber design, the base manifold distributes the single steam/hydrogen inlet flow exiting the steam/hydrogen heat exchanger to the four electrolyzer stacks. It also distributes the single inlet air flow exiting the air/oxygen heat exchanger to a central air-inlet manifold that supplies air to all four stacks. The base manifold also combines the four

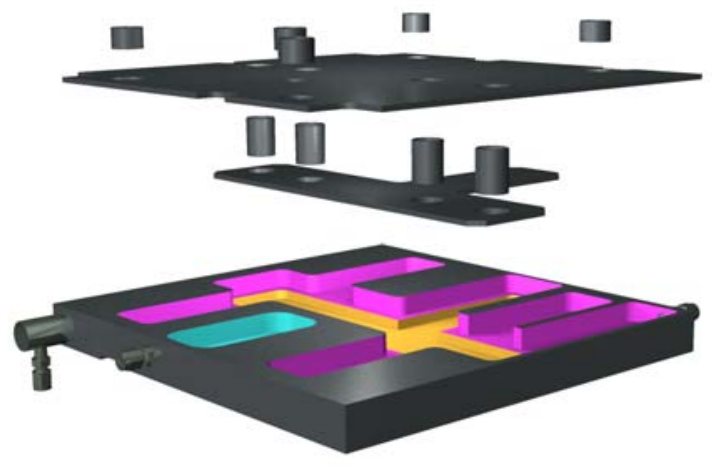

Figure 6. ILS base manifold assembly.

electrolyzer-stack outlet hydrogen flows into a single flow that is supplied to the steam/hydrogen heat exchanger in order to preheat the incoming steam/hydrogen flow. Finally, the base manifold unit collects the air plus oxygen flow that exits the electrolyzer stacks from the air-tight hot-zone volume and directs it through the air/oxygen heat exchanger where is serves to preheat the incoming air.

The overall size and hole-spacing of the heat exchanger was determined in the beginning stages of design so it would fit beneath the existing four-stack electrolysis module. One of the challenges of the design was to be able to direct each of the gas flows to its appropriate port on the bottom side of the electrolysis module. The base manifold was designed as an interface between the heat exchangers and the electrolysis module. A desired feature of the base manifold is its compact height. In the present application, we were constrained by the overall height of the hot zone. The base manifold was designed with a height of only 1.125 inches. As shown in the illustration, the manifold has a lower, T-shaped chamber with four tubes leading to it from above. This lower chamber collects the product hydrogen stream and directs it to the top of the heat exchanger in a single tube. The top, I-shaped level directs the inlet steam into the electrolysis module. The steam enters the module from the heat exchanger in the lower, righthand corner then travels through this upper chamber of the base manifold and exits out the four corners into the four outside edge manifolds of the electrolysis stacks. One small chamber on the left middle portion of the base manifold directs the inlet air from the heat exchanger to the center manifold of the electrolysis module that feeds air to all four stacks in cross flow with respect to the steam-hydrogen. Finally, the tube on the left side of the module collects the air/oxygen stream from the sealed hot zone and directs it to the air heat exchanger below.

\section{HIGH TEMPERATURE BRAZING PROCESS}

Due to the relatively high temperature of operation, the heat exchangers and the base manifold units are fabricated from a high-temperature nickel-chrome alloy Hastalloy-X. The rim pieces and separator plates were laser-cut from 0.200 inch plate stock, then ground flat and parallel to 0.187 -inch prior to brazing. In order to join and seal the multiple layers of 
the heat exchanger and base manifold, a high temperature vacuum brazing process was used. A nickel alloy brazing material, Aerospace Materials Specifications (AMS) 4777 was chosen. This alloy has a composition of $7 \% \mathrm{Cr}, 4.1 \% \mathrm{Si}, 3.0 \%$ $\mathrm{Fe}, 3.0 \% \mathrm{~B}$, with the balance nickel. It provides excellent strength and oxidation resistance at temperatures up to $982^{\circ} \mathrm{C}$. The actual brazing temperature of this material is between 1010 and $1175^{\circ} \mathrm{C}$. Use of a brazing spray-powder deposition method as opposed to the use of a brazing foil was chosen to better control the thickness of the brazing material. Where the surface being brazed is wider, the brazing powder can be applied slightly thicker than in the thin areas. Either of the methods could work, but depth control from the spray method was determined to be preferable.

\section{ASSEMBLY OF HEAT EXCHANGER, BASE MANIFOLD, AND ELECTROLYSIS MODULE}

An exploded view of the entire assembly including the heat exchanger, base manifold unit, and four-stack electrolysis unit is presented in Fig. 7. For each four-stack electrolysis module, there will be two heat exchangers and one base manifold unit. Each base manifold unit has nine flow tubes entering or exiting at its top. An additional advantage of the base manifold unit is that only four flow tubes enter or exit at the bottom of the unit and at the bottom of the heat exchangers, thereby reducing the number of tube penetrations passing through the hot zone base plate from nine to just four. This feature reduces the thermal load on the hot zone base plate.

One problem that was discovered during an initial singlemodule test was that the stainless steel hot zone base plate had been overheated and warped due to high-temperature creep in the region below the module. This overheating was largely due to the fact that ten hot tubes in bundled insulation penetrated the base plate underneath the module, conducting heat to the base plate. By cutting the number of penetrations by more than half, and tightly insulating each tube individually, heat transfer to the base plate will be significantly reduced.

The top portion of the heat exchangers and the top of the base manifold have small, tube stubs that will mate to corresponding slip-fit holes in the mating parts. For example, there are four of these slip-fit holes on the bottom of the base manifold. With high temperature ceramic paste and the weight of the item resting on top, the seal is adequate for the lowpressure system to work with minimal leakage. On the bottom of each heat exchanger are two tubes. These tubes will be a joined to the applicable gas-stream tubes using compression fittings.

\section{INSTALLATION OF THREE ELECTROLYSIS STACKS INTO HOT ZONE}

Fig. 8 shows a rendering of the three ILS electrolysis modules with their base manifolds and heat exchangers beneath. This illustration also shows the instrumentation wires for intermediate voltage and temperature readings. Each module is instrumented with twelve 1/16" sheathed

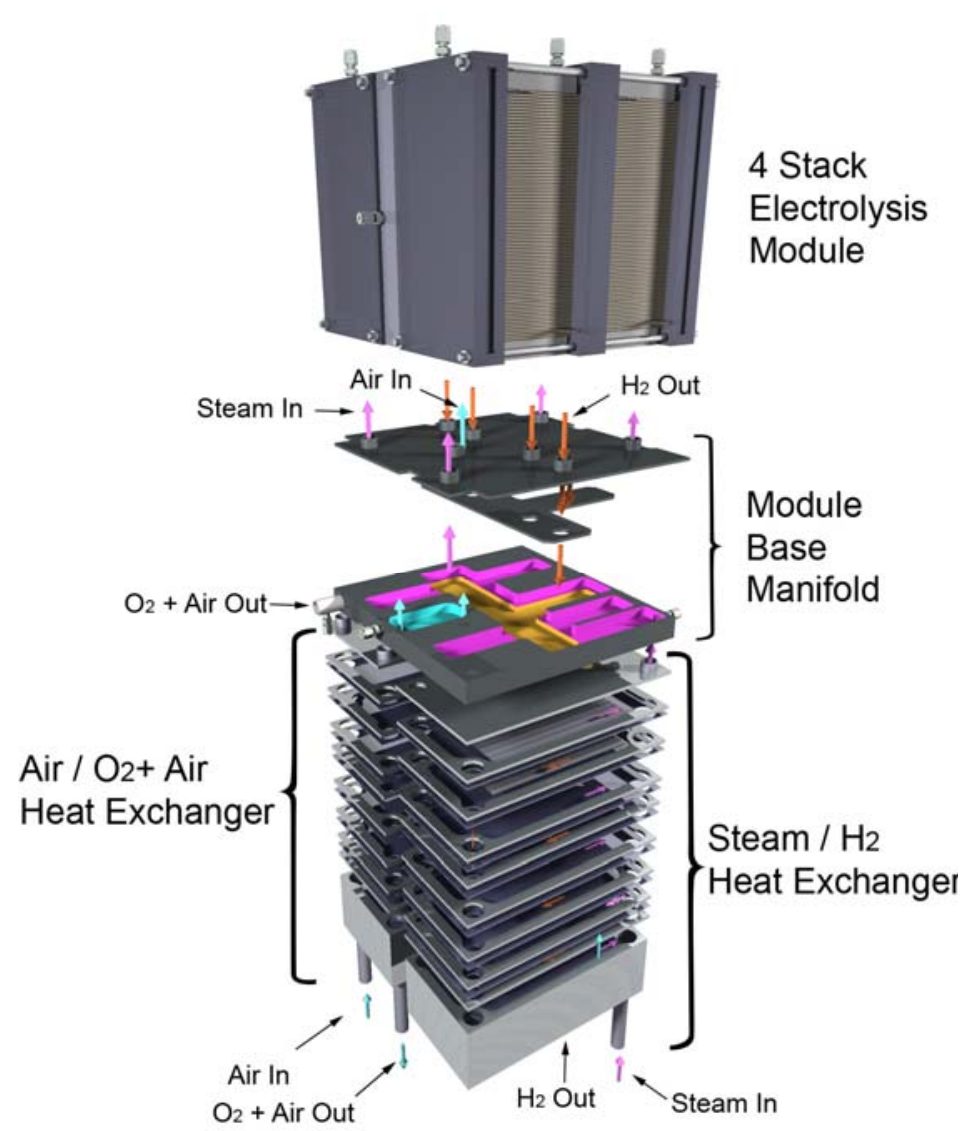

Figure 7. Exploded view of heat exchanger, base manifold unit, and four-stack electrolysis unit.

thermocouples for monitoring gas temperatures in the electrolysis module manifolds and in the base manifold. These thermocouples are attached to the manifolds using compression fittings. There are also twelve miniature 0.020 " diameter inconel-sheathed type- $\mathrm{K}$ thermocouples per module that are used for monitoring internal stack temperatures. Access to the internal region of the stacks is provided via the air outlet face. The internal thermocouples are inserted into the small exit air flow channels. Similarly, seven intermediate voltage tap wires per module are inserted into the air flow channels of the four stacks.

Two compression bars are shown across the top of each module in Fig. 8. These bars are used to maintain compression on all of the stacks during operation in order to minimize electrical contact resistance between the various layers in the stacks. The bars are held in compression via spring-loaded tiedowns. Spring loading allows for a constant compression force to be maintained as thermal expansion occurs during heat-up. The springs are located under the base plate outside of the hot zone.

Note that the heat exchangers are partially imbedded in the insulation thickness. The top portion of each heat exchanger will be exposed to the hot zone radiant environment, which will help to insure that the inlet gas streams achieve the desired electrolyzer operating temperature prior to entering the stacks. 


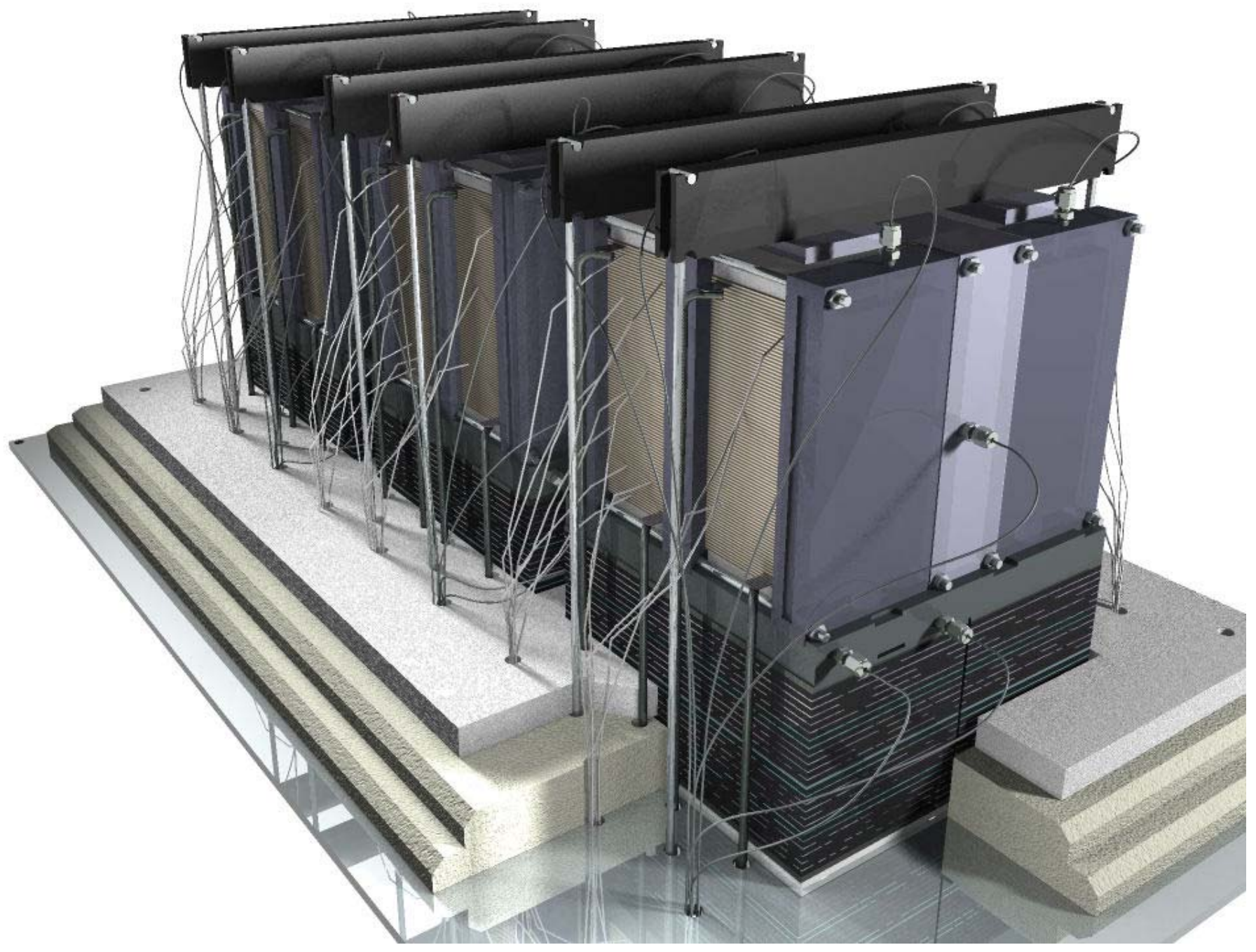

Figure 8. Installation of three electrolysis modules, base manifolds and paired heat exchangers.

The bottom portion of each heat exchanger will be close in temperature to the inlet stream temperature, minimizing the thermal load on the hot zone base plate in the vicinity of the tubing penetrations.

All of the holes in the base plate have to be leak-tight in order to force the outlet air/oxygen to exit the hot zone via the base manifold and heat exchangers. Consequently, the instrumentation and tubing feed-through holes in the hot zone base plate will be sealed using high-temperature ceramic paste. We considered the use of high-temperature sealing gland fittings for all of the instrumentation and tubing feed-throughs, but adopted the ceramic paste option based on cost considerations related to tapping all of the holes in the base plate plus the cost of the fittings themselves.

\section{CONCLUSIONS}

Design of a compact heat exchanger and supporting hardware for heat recuperation in a high-temperature electrolysis application has been presented. The recuperative heat exchanger uses a vacuum-brazed plate-fin design and operates between 300 and $800^{\circ} \mathrm{C}$. It includes corrugated inserts for enhancement of heat transfer coefficients and extended heat transfer surface area. Two recuperative heat exchangers are required per each four-stack electrolysis module. The heat exchangers are mated to a base manifold unit that distributes the inlet and outlet flows to and from the four electrolysis stacks. Design calculations indicate that implementation of the heat recuperation concept will result in more than a factor of two reduction in heater power requirements. In addition, heat losses will be reduced, and the thermal load on the + zone base plate will be minimized.

\section{ACKNOWLEDGMENTS}

This work was supported by the Idaho National Laboratory, Laboratory Directed Research and Development program and by the U.S. Department of Energy, Office of Nuclear Energy, Nuclear Hydrogen Initiative Program. 


\section{COPYRIGHT STATEMENT}

This manuscript has been authored by Battelle Energy Alliance, LLC under Contract No. DE-AC07-05ID14517 with the U.S. Department of Energy. The United States Government retains and the publisher, by accepting the article for publication, acknowledges that the United States Government retains a nonexclusive, paid-up, irrevocable, world-wide license to publish or reproduce the published form of this manuscript, or allow others to do so, for United States Government purposes.

\section{REFERENCES}

1. Stoots, C. M., O'Brien, J. E., Herring, J. S., and Hartvigsen, J. J., "Design and Initial Operation of a MultiKilowatt High Temperature Steam Electrolysis Test Facility at the Idaho National Laboratory," $6^{\text {th }}$ International Fuel Cell Science, Engineering \& Technology Conference, June 16-18, 2008, Denver, CO.

2. O'Brien, J. E., McKellar, M. G., and Herring, J. S., "Performance Predictions for Commercial-Scale HighTemperature Electrolysis Plants Coupled to Three Advanced Reactor Types," ANS International Congress on Advances in Nuclear Power Plants (ICAPP08), June 812, 2008, Anaheim, CA.

3. Incropera, F. P., and DeWitt, D. P., Fundamentals of Heat and Mass Transfer, Third Ed., Wiley, New York, 1990. 